\title{
A novel therapy for colitis utilizing PPAR- $\gamma$ ligands to inhibit the epithelial inflammatory response
}

\author{
Chinyu G. Su, ${ }^{1}$ Xiaoming Wen, ${ }^{1}$ Shannon T. Bailey, ${ }^{2}$ Wen Jiang, ${ }^{1}$ \\ Shamina M. Rangwala, ${ }^{2}$ Sue A. Keilbaugh, ${ }^{1}$ Anne Flanigan, ${ }^{3}$ \\ Sreekant Murthy, ${ }^{3}$ Mitchell A. Lazar, ${ }^{2}$ and Gary D. Wu ${ }^{1}$ \\ ${ }^{1}$ Division of Gastroenterology, and \\ ${ }^{2}$ Division of Endocrinology, Diabetes, and Metabolism, University of Pennsylvania School of Medicine, Philadelphia, \\ Pennsylvania 19104, USA \\ ${ }^{3}$ Division of Gastroenterology and Hepatology, Hahnemann University Hospital, Philadelphia, Pennsylvania 19102, USA \\ Address correspondence and reprint requests to: Gary D. Wu, 600 Clinical Research Building, 415 Curie Boulevard, Philadelphia, \\ Pennsylvania 19104-6144, USA. Phone: (215) 898-0158; Fax: (215) 573-2024; E-mail: gdwu@mail.med.upenn.edu. \\ Chinyu G. Su and Xiaoming Wen contributed equally to this work. \\ Received for publication April 21, 1999, and accepted in revised form June 30, 1999.
}

\begin{abstract}
Peroxisome proliferator-activated receptor $\gamma(\operatorname{PPAR}-\gamma)$, a member of the nuclear hormone receptor superfamily originally shown to play a critical role in adipocyte differentiation and glucose homeostasis, has recently been implicated as a regulator of cellular proliferation and inflammatory responses. Colonic epithelial cells, which express high levels of PPAR- $\gamma$ protein, have the ability to produce inflammatory cytokines that may play a role in inflammatory bowel disease (IBD). We report here that PPAR- $\gamma$ ligands dramatically attenuate cytokine gene expression in colon cancer cell lines by inhibiting the activation of nuclear factor- $\kappa \mathrm{B}$ via an I $\mathrm{\kappa B}-\alpha-$-dependent mechanism. Moreover, thiazolidinedione ligands for PPAR- $\gamma$ markedly reduce colonic inflammation in a mouse model of IBD. These results suggest that colonic PPAR $-\gamma$ may be a therapeutic target in humans suffering from IBD.
\end{abstract}

J. Clin. Invest. 104:383-389 (1999).

\section{Introduction}

Delicately balanced mechanisms maintain the intestinal mucosa in a quiescent state of inflammation. In humans, loss of this balance leads to inflammatory bowel disease (IBD), a chronic debilitating disease that affects millions of people worldwide. The intestinal inflammatory phenotype observed in many immune receptor and cytokine knockout mice models lends support to the notion that cytokines help to regulate and maintain this quiescent state (1). It is now apparent that the intestinal epithelium, which is the interface between the highly antigenic luminal environment and the mucosal immune system, plays an active role in the immune responsiveness of the intestinal mucosa. Intestinal epithelial cells not only express various immune receptors traditionally believed to be expressed primarily by myeloid cell lineages (2), but they can also produce a wide array of immunomodulatory substances such as cytokines and complement factors (3-5). Indeed, specific perturbation of the intestinal epithelium can lead to intestinal inflammation $(6,7)$.

Many immune response genes are regulated by homoand heterodimeric complexes of the nuclear factor- $\mathrm{KB} / \mathrm{Rel}$ (NF-kB/Rel) family of transcription factors. We have previously shown that binding of proteins to the NF- $\mathrm{KB}$ element in the IL- 8 promoter is critical for IL- $1 \beta$-mediated activation of this promoter in intestinal cell lines (8). In most cells, NF- $\mathrm{KB} /$ Rel factors are maintained in an inactive state in the cytoplasm bound to members of the I $\mathrm{kB}$ family of inhibitory proteins (9). Upon cell stimulation by a variety of immunomodulatory substances such as IL-1,
TNF- $\alpha$, PMA, or oxygen radicals, these IKB proteins are rapidly phosphorylated and degraded via the ubiquitinproteosome pathway (10). This enables NF-kB/Rel proteins to translocate from the cytoplasm into the nucleus and activate gene transcription. Inhibitors of NF- $\kappa B$ activation, such as glucocorticoids, have been shown to be very potent anti-inflammatory agents (11).

Recently, ligands for the peroxisome proliferator-activated receptor $\gamma$ (PPAR- $\gamma$ ) have been shown to inhibit the expression of various cytokines in monocytes and macrophages, principally by preventing the activation of NF- $\kappa B / R e l$ by an unknown mechanism $(12,13)$. PPAR- $\gamma$ is a member of the nuclear hormone receptor superfamily whose ligands include several prostanoids including 15deoxy- $\Delta^{12,14}$ prostaglandin $\mathrm{J}_{2}(15 \mathrm{~d}-\mathrm{PGJ} 2)$, polyunsaturated fatty acids, a variety of nonsteroidal anti-inflammatory drugs (NSAIDs), and a new class of oral antidiabetic agents, the thiazolidinediones (TZDs) (14-16). PPAR- $\gamma$ ligands are best characterized as regulators of adipocyte differentiation and glucose homeostasis $(17,18)$.

PPAR- $\gamma$ is also expressed at high levels in both the colonic epithelium and in colon cancer cell lines (19-23). The function of PPAR- $\gamma$ in the colonic epithelium is currently unknown. This is reinforced by recent studies that report that PPAR- $\gamma$ ligands can either increase or decrease colonocyte proliferation depending on the model system studied (21-24). Here we show that the role of PPAR- $\gamma$ in the colon may not be solely, or even primarily, to regulate growth and differentiation, but rather to regulate immune responsiveness. PPAR- $\gamma$ ligands dramatically interfere with the activation of NF- $\mathrm{KB}$ and the ability of 
colonocytes to express immunomodulatory cytokines. Moreover, PPAR- $\gamma$ ligands interfere with the colonic inflammatory process in vivo and, thus, have promise as preventive and therapeutic agents against IBD.

\section{Methods}

Cell culture. Caco-2 and HT-29 cells (American Type Culture Collection, Rockville, Maryland, USA) were maintained in DMEM containing 10\% FBS and penicillin/streptomycin.

RNA analysis. Caco-2 and HT-29 cells were treated with various concentrations of $15 \mathrm{~d}-\mathrm{PGJ}_{2}, \mathrm{BRL} 49653$, ethyl acetate, or DMSO for 24 hours. After RNA isolation and blotting, the Northern blots were hybridized with cDNA probes for IL-8, monocyte chemoattractant protein-1 (MCP-1), and ribosomal 7S (25).

Protein analysis. Proteins were isolated from cells in culture by suspension in RIPA buffer ( $1 \times$ PBS, $1 \%$ Nonidet P$40,0.5 \%$ sodium deoxycholate, $0.1 \%$ SDS) containing 100 $\mu \mathrm{g} / \mathrm{mL}$ PMSF, $60 \mu \mathrm{g} / \mathrm{mL}$ aprotinin, and $1 \mathrm{mM}$ sodium orthovanadate. Cell lysates were centrifuged, and the supernatants were collected and subjected to Western analysis using a 1:200 dilution of an affinity-purified IкB$\alpha$ antibody (sc-203; Santa Cruz Biotechnology Inc., Santa Cruz, California, USA). After a wash in $1 \times$ TTBS containing $0.1 \%$ Tween and a 1 -hour incubation at room temperature with a horseradish peroxidase-conjugated anti-rabbit antibody (1:5,000 dilution; Boehringer Mannhein Biochemicals, Indianapolis, Indiana, USA), the proteins were viewed by enhanced chemiluminescence (Amersham Pharmacia Biotech, Piscataway, New Jersey, USA).

Electrophoretic mobility shift assays (EMSAs) were performed using Caco- 2 cells treated with either methyl acetate (solvent) or $15 \mathrm{~d}_{-} \mathrm{PGJ}_{2}(30 \mu \mathrm{M})$ for 24 hours. The cells were stimulated with complete medium containing IL-1 $\beta(5 \mathrm{ng} / \mathrm{mL})$ for various periods as indicated. Nuclear proteins were isolated from both unstimulated and IL$1 \beta$-stimulated Caco- 2 cells. Double-stranded oligonucleotides spanning the NF- $\kappa B$ element of the IL-8 promoter (8) were labeled with ${ }^{32} \mathrm{P}$. Binding reactions, each containing $10 \mu \mathrm{g}$ of nuclear proteins, were performed as described previously (26). Nuclear proteins were subsequently separated on a $4 \%$ polyacrylamide gel.

Transient cell transfections. Caco- 2 cells were transiently cotransfected with either the IL-8 promoter luciferase reporter plasmid (wt)LUC (8) or the PPAR- $\gamma$-regulated reporter plasmid acyl-CoA X 3-TK-LUC (27) and PCMV$\beta$-gal (transfection control), using the calcium phosphate precipitation method (28). Forty-eight hours after transfection, the cells were treated with various concentrations of $15 \mathrm{~d}-\mathrm{PGJ} \mathrm{J}_{2}$ for 24 hours. Cells were stimulated with IL-1 $\beta(5 \mathrm{ng} / \mathrm{mL})$ for 6 hours, followed by assays for luciferase and $\beta$-gal activity as described previously (29).

Animal treatments. Female 8-week-old Swiss-Webster mice, weighing 25-30 g, were fed standard mice chow pellets and had access to tap water. Acute colitis was induced by feeding the mice $4 \%$ dextran sodium sulfate (DSS; molecular mass $=30-40 \mathrm{kDa}$ dissolved in drinking water) for 7 days. Two treatment studies were performed, one with troglitazone (Rezulin; Parke-Davis, Morris Plains, New Jersey,USA) and the other with BRL 49653. The 2 studies contained 8 animals in each treatment group. In the first protocol, troglitazone was suspended in $0.75 \%$ methylcellulose solution. Zero, 10,30 , and $100 \mathrm{mg} / \mathrm{kg} / \mathrm{d}$ of troglitazone $(0.1 \mathrm{~mL} /$ mouse $)$ was administered by gavage on the day DSS feeding was initiated. After induction of colitis, DSS was discontinued on day 7. Therapy with troglitazone was continued until the mice were sacrificed on day 15 . In the second protocol, colitis was initiated with DSS for 7 days, followed by therapy with BRL 49653 (suspended in 0.75\% methyl-

\section{Figure 1}

PPAR- $\gamma$ ligands inhibit cytokine gene expression in colon cancer cell lines. (a) The Caco-2 colon cancer cell line was treated with various concentrations of $15 \mathrm{~d}-\mathrm{PG} \mathrm{J}_{2}$ for 24 hours before immune stimulation with IL-1 $\beta$ for 90 minutes. (b) Quantitation of IL-8 mRNA expression in Caco- 2 cells treated with various concentrations of $15 \mathrm{~d}-\mathrm{PG} \mathrm{J}_{2}$. Mean $\pm \mathrm{SD}$ of 3 independent determinations. (c and d) HT-29 cells were treated for 24 hours with various concentrations of either $15 \mathrm{~d}-\mathrm{PG} \mathrm{J}_{2}$ (c) or BRL 49653 (d), followed by stimulation with IL-1 $\beta$ for 90 minutes. a

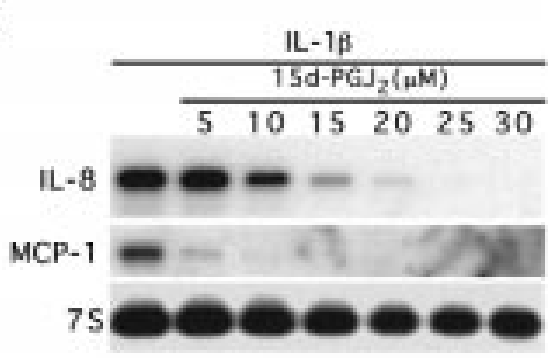

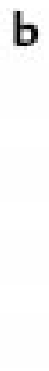

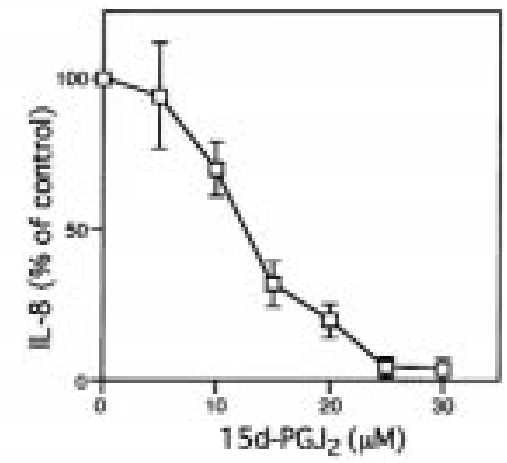

d
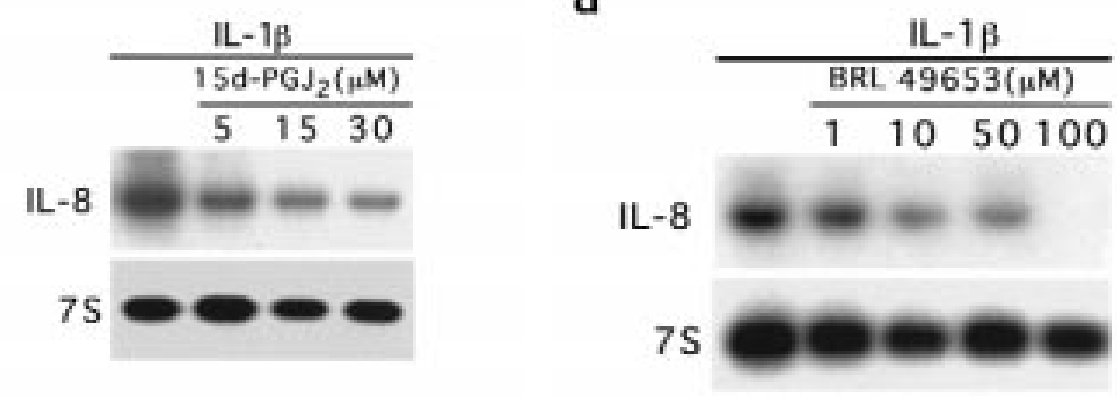


\section{Figure 2}

$15 \mathrm{~d}-\mathrm{PG} \mathrm{J}_{2}$ inhibits the transcriptional activation of the IL- 8 promoter by preventing the activation of NF- $\kappa B$ via an $I \kappa B-\alpha-$ dependent pathway. (a) Caco- 2 cells cotransfected with either an IL-8 promoter luciferase reporter gene or the PPAR- $\gamma$-regulated reporter plasmid, acyl-CoA X 3 TK-LUC, were treated with various concentrations of $15 \mathrm{~d}-\mathrm{PG} \mathrm{J}_{2}$ for 24 hours, followed by stimulation with IL-1 $\beta(5 \mathrm{ng} / \mathrm{mL})$. (b) EMSAs of nuclear extracts isolated from Caco- 2 cells treated with either $15 \mathrm{~d}-\mathrm{PG} \mathrm{J}_{2}$ or methyl acetate for 24 hours and followed by IL-1 $\beta$ stimulation ( 5 $\mathrm{ng} / \mathrm{mL}$ ) for the times indicated. A double-stranded oligonucleotide spanning the NF- $\kappa B$ element in the IL-8 promoter was used as a probe. (c) IKB$\alpha$ Western blot of proteins isolated from Caco- 2 cells treated with $15 \mathrm{~d}$ $\mathrm{PG} \mathrm{J}_{2}$ or methyl acetate for 24 hours and followed by IL- $1 \beta$ stimulation ( 5 $\mathrm{ng} / \mathrm{mL}$ ) for the times indicated.

cellulose at 0 or $20 \mathrm{mg} / \mathrm{kg} / \mathrm{d}$ gavaged orally) for an additional 8 days, at which time the animals were sacrificed for histological analysis. A disease activity index (DAI) was determined on a daily basis for each animal, and consists of a calculated score based on change in body weight, stool consistency, and intestinal bleeding as described previously (30). Parameters for the DAI were measured by an investigator (A. Flanigan) blinded to the protocol. A significant decrease in the DAI is considered an end point of successful therapy.

Histology and immunohistochemistry. Mouse colonic tissues embedded in OCT were cut into 5 - $\mu \mathrm{m}$ sections and dried and fixed in $4 \%$ paraformaldehyde. After a rinse in $1 \times$ PBS, they were treated with $1.5 \% \mathrm{H}_{2} \mathrm{O}_{2}$ in methanol for 20 minutes at room temperature. The sections were then microwaved for 12 minutes in $10 \mathrm{mM}$ citrate acetate ( $\mathrm{pH}$ 6.0). Blocking was performed for 10 minutes with $1 \times$ PBS containing $5 \%$ normal goat serum, and the sections were incubated with an affinity-purified polyclonal antibody for PPAR- $\gamma(31)$ at 1:500 dilution for 30 minutes. After washing with $1 \times$ PBS, the slides were incubated with a biotinylated goat anti-rabbit secondary antibody (Vector Laboratories, Burlingame, California, USA) at a dilution of 1:200 for 30 minutes. Staining was detected by using the horseradish peroxidase VECTASTAIN Elite ABC kit (Vector Laboratories) and 3,3'diaminobenzidine (DAB; Sigma Chemical Co., St. Louis, Missouri, USA). The slides were counterstained in hematoxylin, dehydrated in ethanol and xylene, and mounted with mounting media. Blocking experiments used $10 \mu \mathrm{g}$ of immunogen peptide preincubated with the PPAR- $\gamma$ antibody at $4^{\circ} \mathrm{C}$ overnight.

\section{Results}

Treatment of the Caco- 2 intestinal cell line, previously shown to express PPAR- $\gamma$, with $15 \mathrm{~d}-\mathrm{PGJ}_{2}$ strongly inhibited IL-1 $\beta$-induced expression of both the neutrophil chemoattractant IL- 8 and MCP-1 (Figure 1a). The average of 3 independent experiments showed this inhibitory effect to be dose dependent, with an $\mathrm{EC}_{50}$ of $12 \mu \mathrm{M}$ (Figure $1 \mathrm{~b})$, which is near the $K_{\mathrm{d}}$ of $15 \mathrm{~d}-\mathrm{PG} \mathrm{J}_{2}$ binding to PPAR$\gamma(15,32) .15 \mathrm{~d}-\mathrm{PGJ} \mathrm{J}_{2}$ also inhibited the induction of IL-8 expression in a second intestinal cell line, HT-29, in response to stimulation with either IL- $1 \beta$ (Figure $1 \mathrm{c}$ ) or TNF- $\alpha$ (data not shown). A different ligand for PPAR- $\gamma$, the TZD BRL 49653, also inhibited IL-8 gene expression in a dose-dependent fashion, with an $\mathrm{EC}_{50}$ of $10-50 \mu \mathrm{M}$ a

b
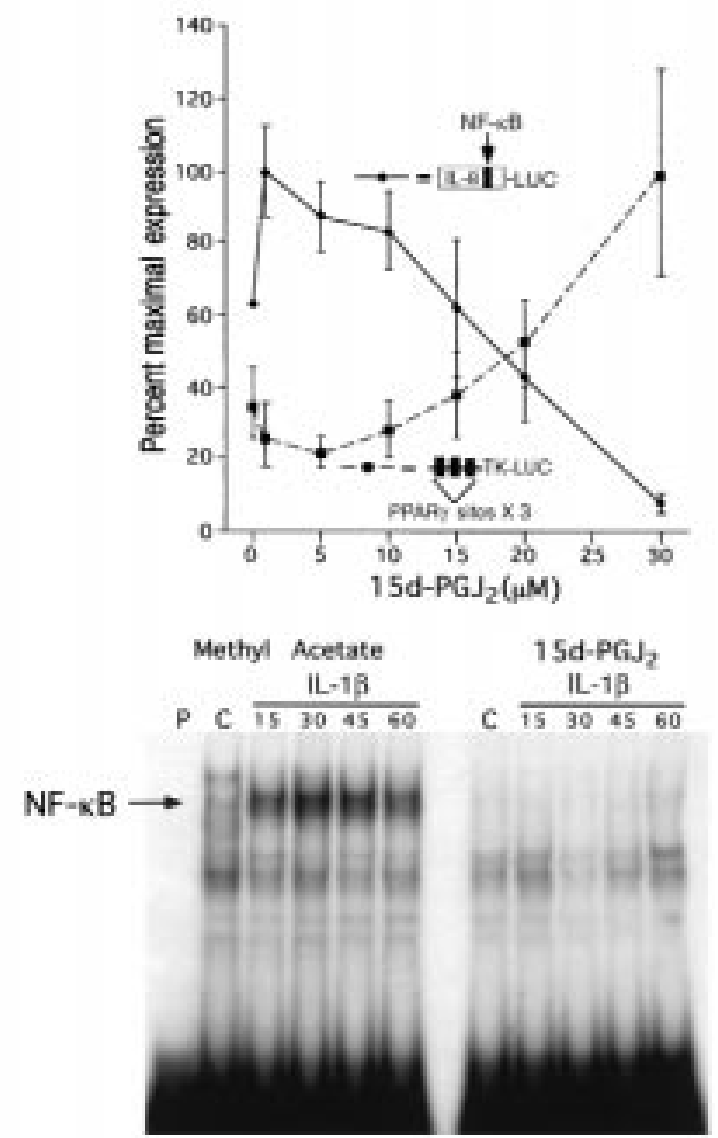

C

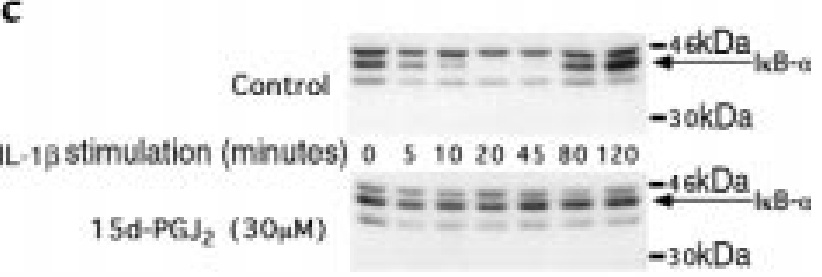

(Figure 1d). Interestingly, although the PPAR- $\alpha$ isoform has been shown to be expressed in colon cancer cell lines (33), treatment of either Caco- 2 or HT-29 cells with the PPAR- $\alpha$-specific ligand WY 14643 did not inhibit the expression of IL-8 (data not shown). This finding is direct contrast to that observed in vascular smooth muscle cells, where ligands for PPAR- $\alpha$, but not PPAR- $\gamma$, inhibit the inflammatory response (34). Therefore, although both PPAR- $\alpha$ and PPAR- $\gamma$ heterodimerize with retinoid X receptor and bind to similar cis-acting elements, their effects on immune responsiveness appear to be tissue specific.

We next investigated the mechanism by which PPAR- $\gamma$ ligands inhibit IL-8 gene expression in colon cancer cells. Consistent with its effect on IL-8 gene expression, $15 \mathrm{~d}-$ $\mathrm{PGJ}_{2}$ inhibited the ability of IL-1 $\beta$ to activate a reporter gene regulated by the IL-8 promoter in a dose-dependent fashion (Figure $2 \mathrm{a}$ ). Moreover, the $\mathrm{EC}_{50}$ of $25 \mu \mathrm{M}$ for inhibition of the IL-8 promoter showed excellent agreement with the activation of transcription from a wellcharacterized positive PPAR- $\gamma$ response element from the acyl-CoA oxidase gene (27), strongly suggesting that the effects of the ligand are mediated by PPAR- $\gamma$. Differences 


\section{Figure 3}

PPAR- $\gamma$ ligands inhibit inflammation and reduce disease severity in the DSS model of murine colitis. (a) Colitis was established after 7 days of $4 \%$ DSS. Day 0 refers to the day that DSS treatment ended. Throughout the entire course of the study, the mice were treated with the amounts of troglitazone indicated. A DAl was determined daily for each animal in the study. ${ }^{*} P=0.009,{ }^{*} P=0.003$ by unpaired $t$ test. (b) Colitis was established after 7 days of $4 \%$ DSS. Day 0 refers to the day that DSS treatment ended and BRL 49653 administration was begun. ${ }^{*} P=0.001,{ }^{*} P=0.008$.
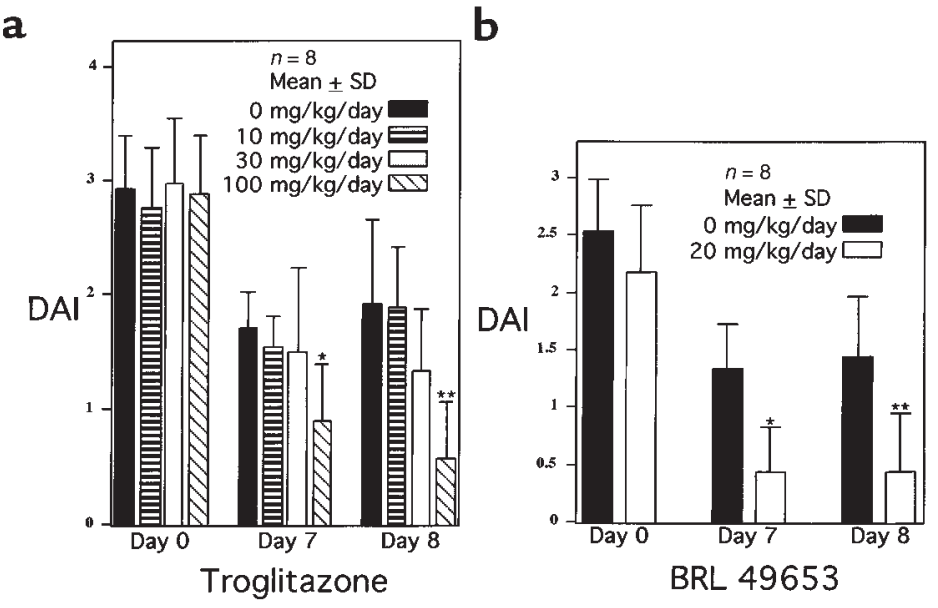

in mRNA stability, translation, and enzymatic activity, alone or in combination, may account for the difference between the $\mathrm{EC}_{50}$ in this reporter gene study and that observed for the inhibition of IL-8 mRNA expression (Figure 1, a and b).

We have previously shown that site-directed mutagenesis of the NF- $\mathrm{kB}$ element within the context of the IL-8 promoter completely eliminates activation in response to stimulation with IL-1 $\beta$ (8). Transfection experiments confirm that this mutated promoter remains completely inactive when Caco- 2 cells are pretreated with $10-30 \mu \mathrm{M}$ $15 \mathrm{~d}-\mathrm{PGJ}_{2}$ (data not shown). EMSAs show that the treatment of Caco- 2 cells with $15 \mathrm{~d}-\mathrm{PGJ}_{2}$ dramatically reduced nuclear protein binding to the NF- $\mathrm{KB}$ element of the IL8 promoter (Figure $2 \mathrm{~b}$ ). In response to immune stimulation, degradation of the IKB family of proteins plays a critical role in the activation of NF- $\mathrm{KB}(9)$. The rapid and transient expression of IL-8 mRNA in Caco- 2 cells in response to IL- $1 \beta$ stimulation is consistent with regula-

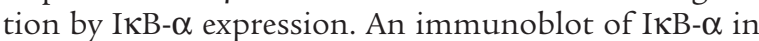
Caco- 2 cells showed that I $\kappa$ B- $\alpha$ protein was rapidly degraded within 10 minutes after stimulation with IL-1 $\beta$, followed by reappearance of the protein at 80 minutes due to autoregulatory induction of this gene by NF- $\kappa B$ (35) (Figure 2c). In contrast, IאB- $\alpha$ was resistant to degradation in IL-1 $\beta$-stimulated Caco- 2 cells treated with $15 \mathrm{~d}$ $\mathrm{PGJ}_{2}$ (Figure $2 \mathrm{c}$ ), consistent with the absence of NF- $\mathrm{\kappa B}$ binding noted on EMSA (Figure $2 \mathrm{~b}$ ).

To determine whether ligands for PPAR- $\gamma$ can attenuate intestinal inflammation in vivo, we studied the effect of 2 different TZD PPAR- $\gamma$ ligands on a well-established murine model of colonic inflammation that is commonly used to screen pharmacologic agents (1). Animals fed $4 \%$ DSS develop colonic inflammation within 7 days; after termination of DSS administration, colonic inflammation slowly resolves (30). The DAI provides a well-characterized method of quantitating disease severity in this model that correlates well with histological healing (30). Two treatment studies were performed, one with troglitazone and the other with BRL 49653. In the first study, mice were treated throughout the entire protocol with various concentrations of troglitazone. The DAI for each study group demonstrated that 7 and 8 days after DSS was discontinued, troglitazone (100 $\mathrm{mg} / \mathrm{kg} / \mathrm{d}$ ) led to a $47 \%$ and $70 \%$ decrease in the DAI, respectively, compared with the placebo-treated group (Figure 3a). Also noted was a trend toward a decrease in the DAI observed in mice treated with an intermediate dose of troglitazone $(30 \mathrm{mg} / \mathrm{kg} / \mathrm{d})$, suggestive of a dosedependent response. Therapeutic efficacy was also determined for BRL 49653 in the same model. BRL 49653 was administered once colitis was established after 7 days of DSS. This eliminated the possibility that the compound altered water consumption while the disease was being initiated with DSS during the first 7 days. Figure $3 \mathrm{~b}$ shows that BRL dramatically decreased the DAI by $67 \%$ and $70 \%$ on days 7 and 8 , respectively.

Immunohistochemistry of the normal colon showed that PPAR- $\gamma$ is expressed predominantly by epithelial cells located in the proliferative crypt compartment (Figure 4a). The specificity of this nuclear staining was confirmed by effective competition using the immunogen peptide. Immunohistochemistry was also performed on tissues obtained from animals treated with DSS (Figure 4b). Colonic tissue from animals that received vehicle alone showed intense mucosal inflammation with a chronic inflammatory infiltrate, edema, and marked thickening of the bowel wall. In contrast, histological sections from the colon of animals treated with 8 days of BRL 49653 showed a remarkable decrease in inflammation with only a mild inflammatory infiltrate, no edema, and normal bowel wall thickness. Immunostaining of these tissue sections demonstrated that PPAR- $\gamma$ was expressed primarily in the colonic epithelium, even in the presence of intense inflammation (Figure 4b). The inflammatory cells expressed comparatively little PPAR$\gamma$, consistent with the colonic epithelium being the target of PPAR- $\gamma$ ligands.

\section{Discussion}

There is significant interest in the biologic consequences of PPAR- $\gamma$ activation in the colon. Because of the differentiating and antiproliferative effects of PPAR- $\gamma$ in adipose and breast tissue $(17,18,36,37)$, it has been proposed that ligands for this receptor may have therapeutic potential in chemoprevention or the treatment of colorectal neoplasia $(21,24)$. Recent studies, however, suggest that these same ligands actually 
enhance colon polyp and tumor formation in the min mouse model of familial adenomatous polyposis coli $(22,23)$. Here we show that PPAR- $\gamma$ ligands have another major effect on colon epithelial cells, namely, to regulate the inflammatory response. Several historical observations are consistent with the possible utility of PPAR- $\gamma$ activation in the treatment of colonic inflammation. First, polyunsaturated fatty acids, such as provided in fish oil, have been shown to be potent activators of PPAR- $\gamma$ and to have efficacy in the treatment of $\operatorname{IBD}(38,39)$. Second, there is evidence that TZDs may decrease insulin resistance by decreasing the production of TNF- $\alpha$ by adipose tissue and/or by inhibiting TNF- $\alpha$-mediated signal transduction (40). Inhibition of TNF- $\alpha$ activity by the use of anti-TNF antibodies has been shown to be an effective treatment modality for refractory Crohn's disease (41).

We show that 2 different classes of ligands for PPAR- $\gamma$ potently inhibit cytokine expression in 2 different PPAR$\gamma$-expressing colon cell lines $(21,24)$. The increased potency of $15 \mathrm{~d}-\mathrm{PGJ}_{2}$ relative to BRL 49653 contrasts with the direct binding affinities of these compounds for PPAR- $\gamma$, but is consistent with the relative potencies of these compounds for negative regulation of genes involved in the inflammatory response $(12,13)$. At present, it is not known why the $\mathrm{EC}_{50}$ for $\mathrm{BRL} 49653$ is greater than that for $15 \mathrm{~d}-\mathrm{PGJ}_{2}$. It is possible that cofactors necessary for transcriptional repression interact with ligand-bound PPAR- $\gamma$ differently than those involved in transcriptional activation (42). We also do not exclude the possibility that these compounds inhibit cytokine gene expression through additional mechanisms independent of PPAR- $\gamma$. Indeed, a PPAR- $\gamma$-independent pathway may be operative in neuronal cells, where investigators have recently shown that $15 \mathrm{~d}-\mathrm{PGJ} \mathrm{J}_{2}$ inhibits inducible nitric oxide synthase (iNOS) expression and promoter activity by inhibiting transcriptional activation via NF- $\mathrm{KB}(43)$. iNOS expression in microglial cells was not inhibited by TZDs, and the nuclear translocation and DNA-binding activities of NF- $\kappa \mathrm{B}$ were unaf-

$\mathbf{a}$
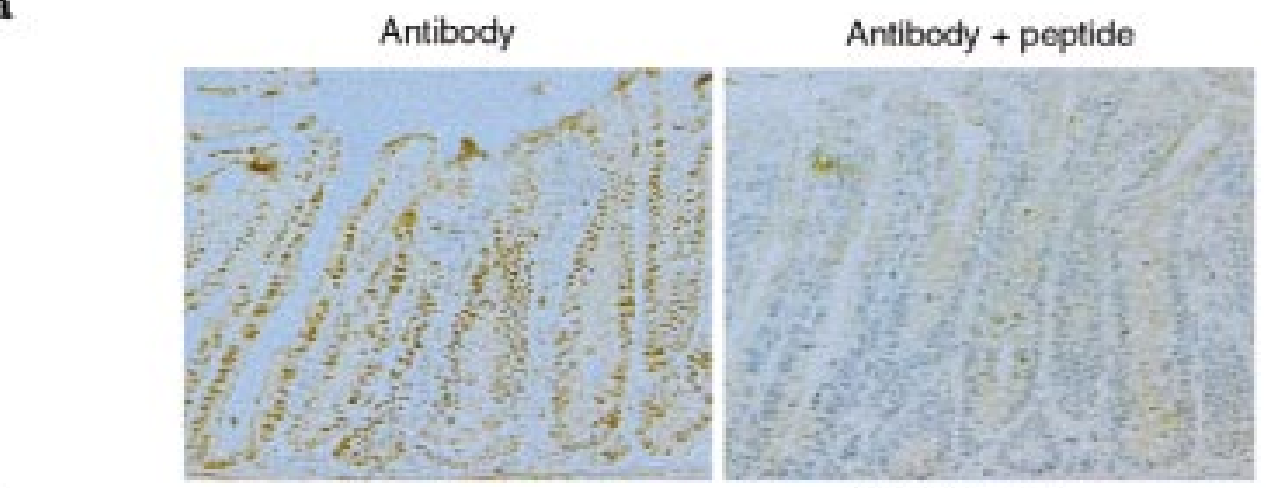

b

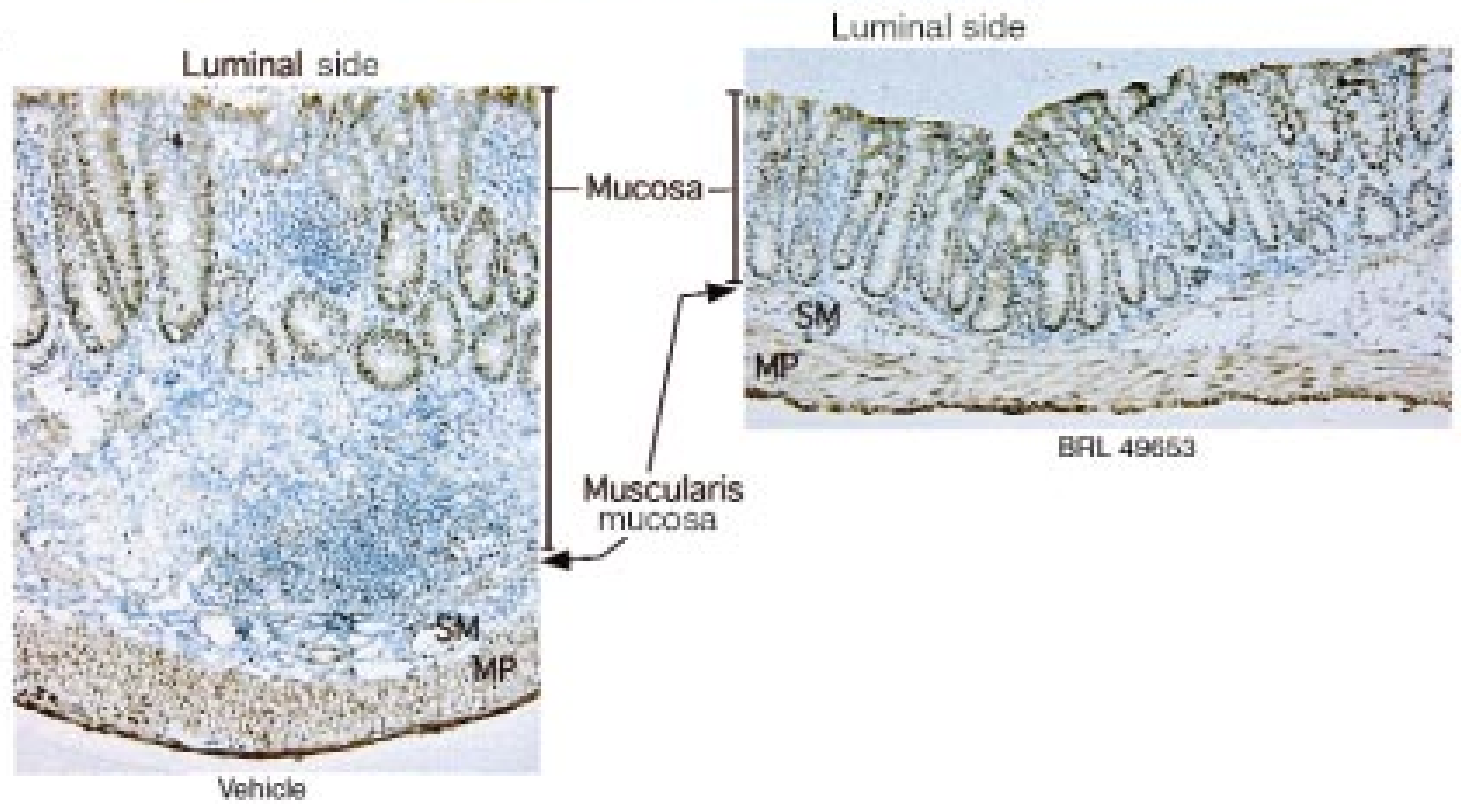

Figure 4

PPAR- $\gamma$ expression is localized specifically to the colonic epithelium in normal and inflamed tissue. (a) Immunohistochemistry for PPAR- $\gamma$ was performed on frozen sections of normal mouse colonic tissue. A peptide blocking experiment is shown on the right. (b) Detection of PPAR- $\gamma$ by immunohistochemistry in colonic tissue obtained from mice treated for 8 days with either vehicle alone or BRL $49653(20 \mathrm{mg} / \mathrm{kg} / \mathrm{d})$. $\times 100$. MP, muscularis propria; SM, submucosa. 
fected by $15 \mathrm{~d}-\mathrm{PGJ}_{2}$. These results, however, are distinctly different from our findings in intestinal cell lines, where BRL 49653 does inhibit IL-8 expression. Furthermore, we show that in Caco- 2 cells, $15 \mathrm{~d}-\mathrm{PGJ}_{2}$ inhibits the nuclear translocation and subsequent DNA binding of $N F-\kappa B$ via an I $\kappa B-\alpha$-dependent pathway by inhibiting the immune response-induced degradation of I $\mathrm{KB}-\alpha$. This is also distinct from the putative non-PPAR pathway of iNOS regulation in neuronal cells. Although further investigation will be required to elucidate the upstream mechanisms by which PPAR- $\gamma$ inhibits the degradation of IKB- $\alpha$, inhibition of both IL- $1 \beta$ - and TNF- $\alpha$-induced IL- 8 gene expression suggests that activation of PPAR- $\gamma$ alters functional elements common to both these pathways. Targeting of NF- $\kappa \mathrm{B}$ as a therapeutic approach to IBD is already established (44).

Although previous studies have shown that activation of PPAR- $\gamma$ inhibits the inflammatory response in monocytes and macrophages, immunolocalization of PPAR- $\gamma$ primarily to colonocytes, even in the presence of inflammation, strongly suggests that these epithelial cells are the target of PPAR- $\gamma$ ligands in this model. This provides evidence that immunomodulation of the intestinal epithelium alone may be efficacious in the treatment of intestinal inflammatory states. We do not exclude the possibility that a component of the anti-inflammatory effect is mediated by the action of TZDs on the systemic immune system. However, the fact that DSS administered rectally can also induce colitis suggests that the inflammatory response is initiated by an effect localized to the colon rather than involving an alteration in the systemic immune system.

The role that PPAR- $\gamma$ ligands may play in neoplasia need not be necessarily viewed as a disparate effect. Indeed, it is well known that chronic intestinal inflammation not only alters patterns of cellular proliferation and differentiation in the intestinal epithelium, but is also a significant factor in the development of colorectal neoplasia $(45,46)$. At the present time, the effect of PPAR- $\gamma$ agonists on colonic epithelial cell growth is controversial. Two studies show that these ligands have potent antineoplastic and antiproliferative activities both in vivo and in vitro $(21,24)$. In contrast, the 2 studies showing that TZD ligands increase the number of colonic polyps utilize the min mouse model of intestinal polyposis $(22,23)$. The proneoplastic effect observed, therefore, occurs in a single murine model related to an adenomatous polyposis coli gene (APC) mutation. The relevance of the min mouse model to IBD is uncertain, particularly because APC mutations are rare in colitis-induced neoplasia (47). Furthermore, highly unsaturated fatty acids, which are known natural ligands for PPAR- $\gamma$, are well known not only to reduce the risk of colonic tumors, but also as an effective treatment for intestinal inflammation $(38,48,49)$, supporting the antineoplastic role of PPAR- $\gamma$. At this point, therefore, it is premature to conclude that PPAR- $\gamma$ ligands will induce colonic neoplasia in any background, but particularly in the setting of intestinal inflammation. In fact, an equally compelling case could be made that these compounds may protect against the development of neoplasia associated with colitis. Further investigation into the effect of PPAR- $\gamma$ ligands on neoplastic transformation in the set- ting of IBD may provide important insights into the biology of the colonic epithelium.

PPAR- $\gamma$ ligands represent a novel approach to the treatment of IBD. The TZD ligands used in the animal studies were well within the doses needed for insulin sensitization and have been shown to be well tolerated by mice (21). The DAIs used to quantitate disease activity in our animal studies are comprehensive functional measures that are analogues to the subjective clinical symptoms observed in humans with ulcerative colitis. Many antiinflammatory pharmaceuticals have been studied in the DSS model of colitis that show efficacy paralleling the clinical response observed in humans (30, 50-53). In fact, the results with either troglitazone or BRL 49653 show a greater level of therapeutic efficacy than that observed with Olsalazine (Dipentum; Pharmacia and Upjohn, Kalamazoo, Michigan, USA); (150 mg/kg/d) (51). Therefore, the highly significant anti-inflammatory effect observed with the DSS model provides the single best indication that PPAR- $\gamma$ ligands may have clinical efficacy in patients with IBD.

\section{Acknowledgments}

This work was supported by National Institutes of Health grants DK-47709 and AI-39368 (to G.D. Wu); Center Grant P30 DK-50306; DK-49780 and DK-49210 (to M.A. Lazar).

1. Elson, C.O., Sartor, R.B., Tennyson, G.S., and Riddell, R.H. 1995. Experimental models of inflammatory bowel disease. Gastroenterology. 109:1344-1367

2. Reinecker, H.C., and Podolsky, D.K. 1995. Human intestinal epithelial cells express functional cytokine receptors sharing the common $\gamma_{\mathrm{c}}$ chain of the interleukin 2 receptor. Proc. Natl. Acad. Sci. USA. 92:8353-8357.

3. McCormick, B.A., et al. 1995. Surface attachment of Salmonella typhimuri$u m$ to intestinal epithelia imprints the subepithelial matrix with gradients chemotactic for neutrophils. J. Cell Biol. 131:1599-1608.

4. Jung, H.C., et al. 1995. A distinct array of proinflammatory cytokines is expressed in human colon epithelial cells in response to bacterial invasion. J. Clin. Invest. 95:55-65.

5. Andoh, A., Fujiyama, Y., Bamba, T., and Hosoda, S. 1993. Differential cytokine regulation of complement $\mathrm{C} 3, \mathrm{C} 4$, and factor B synthesis in human intestinal epithelial cell line, Caco-2. J. Immunol. 151:4239-4247.

6. Hermiston, M.L., and Gordon, J.I. 1995. Inflammatory bowel disease and adenomas in mice expressing a dominant negative N-cadherin. Science. 270:1203-1207.

7. Baribault, H., Penner, J., Iozzo, R.V., and Wilson-Heiner, M. 1994. Colorectal hyperplasia and inflammation in keratin 8-deficient FVB/N mice. Genes Dev. 8:2964-2973.

8. Wu, G.D., Lai, E.J., Huang, N., and Wen, X. 1997. Oct-1 and C/EBP bind to overlapping elements within the IL- 8 promoter: the role of Oct- 1 as a ranscriptional repressor. J. Biol. Chem. 272:2396-2403.

9. Verma, I.M., Stevenson, J.K., Schwarz, E.M., Antwerp, D.V., and Miyamo-

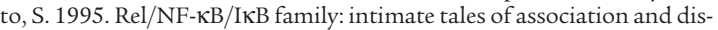
ociation. Genes Dev. 9:2723-2735.

10. Brown, K., Gerstberger, S., Carlson, L., Franzoso, G., and Siebenlist, U. 1995. Control of IKB- $\alpha$ proteolysis by site-specific, signal-induced phosphorylation. Science. 267:1485-1488.

11. Auphan, N., DiDonate, J.A., Rosette, C., Helmberg, A., and Karin, M. 1995. Immunosuppression by glucocorticoids: inhibition of NF- $\mathrm{KB}$ activity through induction of IKB synthesis. Science. 270:286-290.

12. Ricote, M., Li, A.C., Willson, T.M., Kelly, C.J., and Glass, C.K. 1998. The peroxisome proliferator-activated receptor- $\gamma$ is a negative regulator of macrophage activation. Nature. 391:79-82.

13. Jiang, C., Ting, A.T., and Seed, B. 1998. PPAR- $\gamma$ agonists inhibit production of monocyte inflammatory cytokines. Nature. 391:82-86.

14. Yu, K., et al. 1995. Differential activation of peroxisome proliferator-activated receptors by eicosanoids. J. Biol. Chem. 270:23975-23983.

15. Kliewer, S.A., et al. 1995. A prostaglandin J2 metabolite binds peroxisome proliferator-activated receptor $\gamma$ and promotes adipocyte differentiation. Cell. 83:813-819.

16. Forman, B.M., et al. 1995. 15-deoxy delta 12, 14-prostaglandin J2 is a ligand for the adipocyte determination factor PPAR $\gamma$. Cell. 83:803-812. 
17. Tontonoz, P., Hu, E., and Spiegelman, B.M. 1994. Stimulation of adipogenesis in fibroblasts by PPAR $\gamma 2$, a lipid-activated transcription factor. Cell. 79:1147-1156.

18. Chawla, A., Schwarz, E.J., Dimaculangan, D.D., and Lazar, M.A. 1994 Peroxisome proliferator-activated receptor $\gamma(\operatorname{PPAR} \gamma)$ : adipose predominant expression and induction early in adipocyte differentiation. Endocrinology. 135:798-800.

19. Fajas, L., et al. 1997. The organization, promoter analysis, and expression of the human PPAR $\gamma$ gene. J. Biol. Chem. 272:18779-18789.

20. Dubois, R.N., et al. 1998. The nuclear eicosanoid receptor, PPAR $\gamma$, is aberrantly expressed in colonic cancers. Carcinogenesis. 19:49-53.

21. Sarraf, P., et al. 1998. Differentiation and reversal of malignant changes in colon cancer through PPAR $\gamma$. Nat. Med. 4:1046-1052.

22. Saez, E., et al. 1998. Activators of the nuclear receptor PPAR $\gamma$ enhance colon polyp formation. Nat. Med. 4:1058-1061.

23. Lefebvre, A.M., et al. 1998. Activation of the peroxisome proliferator-activated receptor $\gamma$ promotes the development of colon tumors in C57BL/6J-APC Min/+ mice. Nat. Med. 4:1053-1057.

24. Brockman, J.A., Gupta, R.A., and Dubois, R.N. 1998. Activation of PPAR $\gamma$ leads to inhibition of anchorage independent growth of human colorectal cancer cells. Gastroenterology. 115:1049-1055.

25. Huang, N., Katz, J.P., Martin, D.R., and Wu, G.D. 1997. Inhibition of IL8 gene expression in Caco- 2 cells by compounds which induce histone hyperacetylation. Cytokine. 9:27-36.

26. Traber, P.G., Wu, G.D., and Wang, W. 1992. Novel DNA-binding proteins regulate intestine-specific transcription of the sucrase-isomaltase gene. Mol. Cell. Biol. 12:3614-3627.

27. Adams, M., Reginato, M.J., Shao, D., Lazar, M.A., and Chatterjee, V.K. 1997. Transcriptional activation by peroxisome proliferator-activated receptor $\gamma$ is inhibited by phosphorylation at a consensus mitogen-activated protein kinase site. J. Biol. Chem. 272:5128-5132.

28. Chen, C., and Okayama, H. 1987. High-efficiency transformation of mammalian cells by plasmid DNA. Mol. Cell. Biol. 7:2031-2034.

29. Wu, G.D., Wang, W., and Traber, P.G. 1992. Isolation and characterization of the human sucrase-isomaltase gene and demonstration of intestine-specific transcriptional elements. J. Biol. Chem. 267:7863-7870.

30. Cooper, H.S., Murthy, S.N.S., Shah, R.S., and Sedergran, D. 1993. Clinicopathologic study of dextran sulfate sodium experimental murine colitis. Lab. Invest. 69:238-249.

31. Xue, J.C., Schwartz, E.J., Chawla, A., and Lazar, M.A. 1996. Distinct stages in adipogenesis revealed by retinoid inhibition of differentiation after induction of PPAR $\gamma$. Mol. Cell. Biol. 16:1567-1575.

32. Shao, D., et al. 1998. Interdomain communication regulating ligand binding by PPAR- $\gamma$. Nature. 396:377-380.

33. Suzuki, R., Suruga, K., Goda, T., and Takase, S. 1998. Peroxisome proliferator enhances gene expression of cellular retinol-binding protein, type II in Caco- 2 cells. Life Sci. 62:861-871.

34. Staels, B., et al. 1998. Activation of human aortic smooth-muscle cells is inhibited by PPAR $\alpha$ but not by PPAR $\gamma$ activators. Nature. 393:790-793.

35. Sun, S.C., Ganchi, P.A., Ballard, D.W., and Greene, W.C. 1993. NF-kB controls expression of inhibitor $\mathrm{I} \kappa \mathrm{B} \alpha$ : evidence for an inducible autoregulatory pathway. Science. 259:1912-1915
36. Tontonoz, P., Hu, E., Graves, R.A., Budavari, A.I., and Spiegelman, B.M. 1994. mPPAR $\gamma 2$ : tissue-specific regulator of an adipocyte enhancer. Genes Dev. 8:1224-1234.

37. Mueller, E., et al. 1998. Terminal differentiation of human breast cancer through PPAR $\gamma$. Mol. Cell. 1:465-470.

38. Kliewer, S.A., et al. 1997. Fatty acids and eicosanoids regulate gene expression through direct interactions with peroxisome proliferator-activated receptors $\alpha$ and $\gamma$. Proc. Natl. Acad. Sci.USA. 94:4318-4323.

39. Belluzzi, A., et al. 1996. Effect of enteric-coated fish-oil preparation on relapses in Crohn's disease. N. Engl. J. Med. 334:1557-1560.

40. Peraldi, P., Xu, M., and Spiegelman, B.M. 1997. Thiazolidinediones block tumor necrosis factor--induced inhibition of insulin signaling. J. Clin. Invest. 100:1863-1869.

41. Targan, S.R., et al. 1997. A short-term study of chimeric monoclonal antibody CA2 to tumor necrosis factor (alpha) for Crohn's disease. $N$. Engl. J. Med. 337:1029-1035.

42. Onate, S.A., Tsai, S.Y., Tsai, M.J., and O’Malley, B.W. 1995. Sequence and characterization of a coactivator for the steroid hormone receptor superfamily. Science. 270:1354-1357.

43. Petrova, T.V., Akama, K.T., and Van Elkdik, L.J. 1999. Cyclopentenone prostaglandins suppress activation of microglia: down-regulation of inducible nitric-oxide synthase by 15 -deoxy- $\Delta^{12,14}$-prostaglandin $\mathrm{J}_{2}$. Proc. Natl. Acad. Sci. USA. 96:4668-4673.

44. Neurath, M.F., Pettersson, S., Buschenfelde, K.H.M., and Strober, W. 1996. Local administration of antisense phosphorothioate oligonucleotides to the $\mathrm{p} 65$ subunit of NF- $\mathrm{\kappa B}$ abrogates established experimental colitis in mice. Nat. Med. 2:998-1004.

45. Serafini, E.P., Kirk, A.P., and Chambers, T.J. 1981. Rate and pattern of epithelial cell proliferation in ulcerative colitis. Gut. 22:648-652.

46. Bachwich, D.R., Lichtenstein, G.R., and Traber, P.G. 1994. Cancer in inflammatory bowel disease. Med. Clin. North Am. 78:1399-1412.

47. Tarmin, L., et al. 1995. Adenomatous polyposis coli gene mutations in ulcerative colitis-associated dysplasias and cancers versus sporadic colon neoplasms. Cancer Res. 55:2035-2038.

48. Reddy, B.S., and Sugie, S. 1988. Effect of different levels of omega-3 and omega- 6 fatty acids on azoxymethane-induced colon carcinogenesis in F344 rats. Cancer Res. 48:6642-6647.

49. Stenson, W.F., Cort, D., Rodgers, J., and Burakoff, R. 1992. Dietary supplementation with fish oil in ulcerative colitis. Ann. Intern. Med. 116:609-614

50. Murthy, S.N.S., et al. 1993. Treatment of dextran sulfate sodium-induced murine colitis by intracolonic cyclosporine. Dig. Dis. Sci. 38:1722-1734.

51. Murthy, S., Murthy, N.S., Coppola, D., and Wood, D.L. 1997. The efficacy of BAY y 1015 in dextran sulfate model of mouse colitis. Inflamm. Res. 46:224-233.

52. Kojouharoff, G., et al. 1997. Neutralization of tumor necrosis factor (TNF) but not IL-1 reduces inflammation in chronic dextran sulfate sodium-induced colitis in mice. Clin. Exp. Immunol. 107:353-358.

53. Bennett, C.F., et al. 1997. An ICAM-1 antisense oligonucleotide prevents and reverses dextran sulfate sodium-induced colitis in mice. J. Pharmacol. Exp. Ther. 280:988-1000. 